\title{
The Effect of Pneumonic Pasteurellosis on Apoptosis and Nitric Oxide Synthase in the Lungs in Calves
}

\author{
Orhan Yavuz ${ }^{1, a, *}$, Güngör Çağdaş Dinçel ${ }^{2, b}$ \\ ${ }^{1}$ Department of Pathology, Faculty of Veterinary Medicine, Aksaray University, 68100 Aksaray, Turkey \\ ${ }^{2}$ Laboratory and Veterinary Assistance Services, Eskil Vocational School, Aksaray University, 68100 Aksaray, Turkey
}

*Corresponding author

\section{A R T I C L E I N F O A B S T R A C T}

Research Article

Pneumonic Pasteurellosis (PP) is an infectious disease caused by Pasteurella multocida and Mannheimia haemolytica, mostly observed in cattle, sheep and calves. PP is characterized by fibrinous bronchopneumonia and pleuritis in the lungs. In this study, it was aimed to determine Caspase-3, Caspase-9, inducible nitric oxide synthase and neuronal nitric oxide synthase expressions by immunohistochemical methods in the lungs suffered from PP. For this purpose, twenty lung tissues were collected from calves with PP. For the Control Group, ten lungs of calves were collected from Aksaray Slaughterhouse. After necropsies of calves were confirmed to be PP by bacteriological examinations. Then the routine histological process was performed to tissues, and stained by Hematoxylin \& Eosin for histopathology, and Caspase-3, Caspase-9, inducible nitric oxide synthase and neuronal nitric oxide synthase antibody staining for immunohistochemistry. The immunohistochemical findings indicated that Caspase-3, Caspase-9, inducible nitric oxide synthase and neuronal nitric oxide synthase positive reactions were seen in alveolar, bronchial and bronchiolar epithelia, and desquamated inflammatory cells in the lumens. In addition, the peripheral neural extensions were immunopositive for neuronal nitric oxide synthase and vascular endothelial cell were positive for inducible nitric oxide synthase. The findings can contribute to a better understanding of expressions of molecules such as Caspase and nitric oxide synthase. These results show that apoptosis and nitric oxide synthase expressions have triggered by airway epithelia and inflammatory cells in the lungs with Pneumonic Pasteurellosis in calves.

vetorhanyavuz@gmail.com (iD) http://orcid.org/0000-0002-1218-4295

b@gcdincel@yahoo.com.tr

https://orcid.org/0000-0002-6985-3197

(c) () \&) This work is licensed under Creative Commons Attribution 4.0 International License

\section{Introduction}

Pneumonic Pasteurellosis (PP) is one of the most common diseases all over the World (Lopez and Martinson, 2017). The disease is also known as Shipping Fever (Çiftçi et al., 2015). PP is characterized by severe fibrinous bronchopneumonia in cattle, sheep, goat and swine (Rice et al., 2007). This type of pneumonia characterized by the presence of fibrin in the inflammatory exudate is called fibrinous bronchopneumonia. The lesions in this pneumonia are also called lobar pneumonia because they are mostly distributed at the lobe level. PP is induced by Pasteurella multocida and Mannheimia haemolytica (Çiftçi et al., 2015). Gram (-) and non-mobile bacteria that have some virulence factors such as leucotoxin, lipopolysaccharide and outer membrane protein (Boyce et al., 2004; Singh et al., 2011). The agents present in the normal flora in tonsil and nasal mucosal tissues in healthy calves, cause disease by triggering stress and some viral infections (Rice et al., 2007).
Apoptosis, by its most basic definition, is programmed cell death. Intrinsic and extrinsic pathways play a role in the formation of apoptosis in the tissues (McIlwain et al., 2013). The intrinsic pathway (also known as mitochondrial pathway) is triggered by DNA damage and internal insults such as reactive oxygen species (ROS), cytokines, toxins (Philchenkov, 2004). The extrinsic pathway is activated by ligands binding to death receptors such as Tumor Necrosis Factor (TNF) and CD95 (McIlwain et al., 2013). Caspases are proteases that induce programmed cell death (apoptosis) that allows damaged or excess cells to be eliminated without damaging their environment (Reed, 2000). Nitric oxide synthase (NOS), is produced by three isoforms [inducible NOS (iNOS), endothelial NOS (eNOS) and neuronal NOS (nNOS)] of NO synthase (Daff, 2010; Förstermann and Sessa, 2012). All three isoforms are expressed in the lungs in animals (Gaston et al., 1994). 
In this study it was aimed that to investigate the effect of PP on Caspase-3, Caspase-9, iNOS and nNOS expression in lung tissue in calves by immunohistochemical methods.

\section{Material and Methods}

\section{Ethical Aspects}

According to following chapter of 02.15.2014 dated and 28914 law numbered "Regulation on Working Procedures and Principles of Animal Experiments Ethics Committee" named regulation which was published in the official gazette by Republic of Turkey Ministry of Agriculture and Forestry; ethics committee approval was not required for the study. Chapter $2 / 8 / \mathrm{k} / 2$ : "Procedures performed with dead animals or tissue, slaughterhouse materials, aborted fetuses are not subject to the permission of the Local Ethics Committee for Animal Experiments."

\section{Material}

The lung tissues of 20 dead calves which had respiratory problems and brought to Aksaray University Veterinary Faculty Pathology Department for necropsy were included in the study for Pneumonia Group (PN Group). In the necropsies, it was confirmed that the lungs had fibrinous bronchopneumonia. Bacterial examination revealed Pasteurella spp. in 4 cases and Mannheimia spp. in 16 cases. During the gross examination, photographs were taken and the findings were recorded. For the control group, lung tissues of 10 healthy calves were obtained from a slaughterhouse.

\section{Histopathological Method}

After the necropsy, lung tissues samples were put into a $10 \%$ formalin solution. Following fixation procedure, the lung tissues were inoculated with alcohol, xylene and paraffin wax. Then, the sections were cut at $5 \mu \mathrm{m}$ by a microtome and mounted on slides. The tissue sections were immersed three times for 5 minutes each in xylene and then in $96 \%, 90 \%, 80 \%, 70 \%$ and $50 \%$ alcohol for rehydration, respectively. In the end of these procedures, the lung tissue sections were stained with Haematoxylin \& Eosin stain. All sections were examined under a light microscope and photographed.

\section{Immunohistochemical Method}

For immunohistochemical staining indirect immunohistochemical method was applied. For this purpose, the $5 \mu \mathrm{m}$ thick paraffin lung tissue sections were placed on positive charged slides. Dewaxed and rehydrated sections incubated in $60^{\circ} \mathrm{C}$ oven for 15 minutes. After this stage, the sections were boiled for 20 minutes in citrate buffer solution for heat induced epitope retrieval (HIER). To block endogenous peroxidase activity, $3 \% \mathrm{H}_{2} \mathrm{O}_{2}$ was dropped onto slides at room temperature for 10 minutes. After that, the firstly block solution was added for 5 minutes, and then the primary antibodies [Anti-Caspase-3 Antibody (Santa Cruz Biotechnology, inc. sc-7272), AntiCaspase-9 Antibody (Santa Cruz Biotechnology, inc. sc73548), Anti-NOS2 Antibody (Santa Cruz Biotechnology, inc. sc-7271) and Anti-NOS1 Antibody (Santa Cruz Biotechnology, inc. sc-55521)] were incubated for 2 hours. After the incubation of primary antibodies, a biotinylated secondary antibody and streptavidin solution were distilled on slides for 15-minute intervals, respectively. Then, the sections stained with aminoethyl carbazole (AEC) and Haematoxylin. Finally, tissue sections were covered by coverslip. In order to negative control, the slides were stained in the same procedure, however Phosphate Buffer Saline (PBS) was used instead of the primary antibody. All sections were examined under a light microscope and photographed (Olympus BX51, Tokyo, Japan).

\section{Immunohistochemical Scoring}

Image J (V1.52a) program was used for immunohistochemical scoring of the cases. Five images were taken from each bronchi, bronchiole and alveoli structures with $400 \times$ magnification. Immunohistochemical staining surface areas in these structures were obtained as percentages. The mean value of 5 staining surface areas of each bronchi, bronchiole and alveoli structures were accepted as the score of one case. In order to prevent errors during scoring, artifacts in the lumens of these structures were excluded.

\section{Statistical Analysis}

Statistical analyses were performed by IBM $®$ SPSS $®$ Statistics Version 22 program. The significance of immunohistochemical findings was determined by Kruskal Wallis and Tamhane tests. $\mathrm{P}<0.05$ was accepted as the difference between the groups.

\section{Results}

\section{Histopathological Results}

Microscopically, congestion, red consolidation and grey consolidation stages were detected in 18 cases. In congestion stage, neutrophil granulocytes and desquamated epithelial cells and edema fluid were seen in the alveolar lumens. Hyperemia was prominent in the capillary vessels in the interalveolar areas. During the red consolidation stage, dense neutrophil granulocytes, desquamated epithelial cells, edema fluid and fibrin deposits were found in the lumens of alveoli. Hyperemia was also detected in the capillary vessels around the alveoli in this stage (Figure 1A). In the gray consolidation period, edema and hyperemia were disappeared (Figure 1B). Thickening of the interlobular interstitium due to thrombotic lymph vessel, edema and fibrin accumulation was also observed in these areas where pneumonia was observed (Figure 1C).

\section{Immunohistochemical Results}

The immunohistochemical result are given in the Figure 2. According to this, Caspase- 3 expressions were mostly found in the exudate in the alveolar lumens and in the epithelium of the alveoli, bronchi and bronchioles (Figure 3A). Similarly, Caspase- 9 expressions were found in the exudate in the lumens and the epithelia of the alveoli, bronchi and bronchioles. However, Caspase- 9 expressions were more prominent in bronchial epithelia (Figure 3B-C). nNOS expressions were detected in the exudate of lumens, and smooth muscle cells around the bronchi, as well as the epithelia of the alveoli, bronchi and bronchioles (Figure 3D). Additionally, nNOS positive staining was also obtained in neuronal extensions in the interstitial area. iNOS expressions were found to be positive in alveolar, bronchial and bronchiole epithelia and vascular endothelium (Figure 3E-F). 


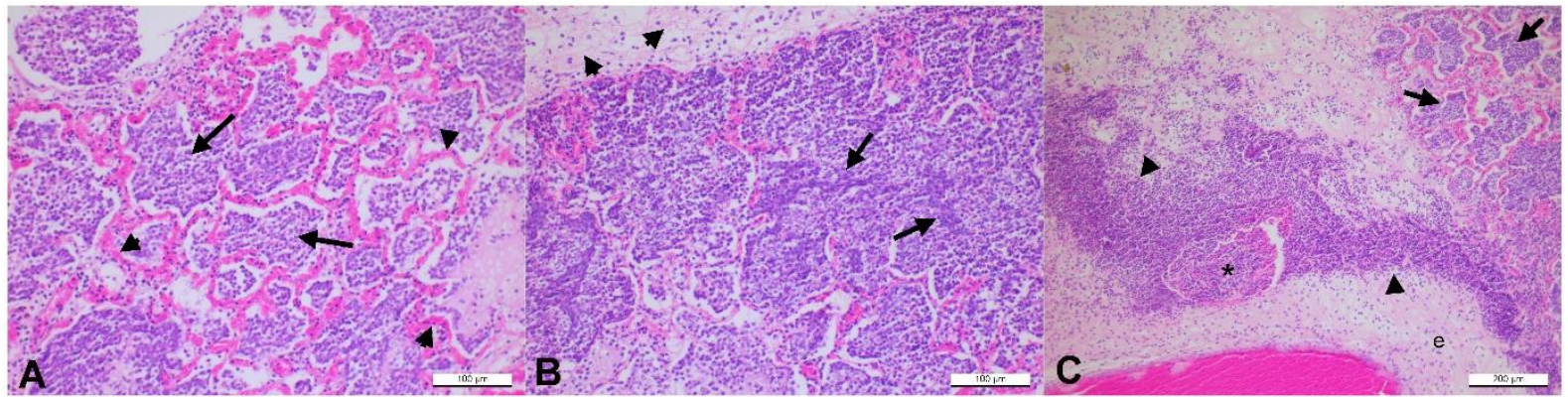

Figure 1. Histopathological staining of the lungs.

A. Red consolidation stage. Hyperemia in the capillary vessels around the alveoli (arrowheads), and neutrophil granulocyte, alveolar macrophage, edema and fibrin accumulation in the lumens of the alveoli (arrows). HE. Bar: $100 \mu \mathrm{m}$. B. Gray consolidation stage. Edema and fibrin accumulation in the interlobular area (arrowheads). Spindle shaped oat cells in the lumens of the alveoli (arrows). HE. Bar: 100um. C. Thickening of the interlobular area due to fibrin, edema (e), inflammatory cell accumulation (arrowheads) and thrombosis in the lymph vein (asterisk). Red consolidation stage in the alveoli (arrows). HE. Bar: $200 \mu \mathrm{m}$.

Immunohistochemical Staining Rate

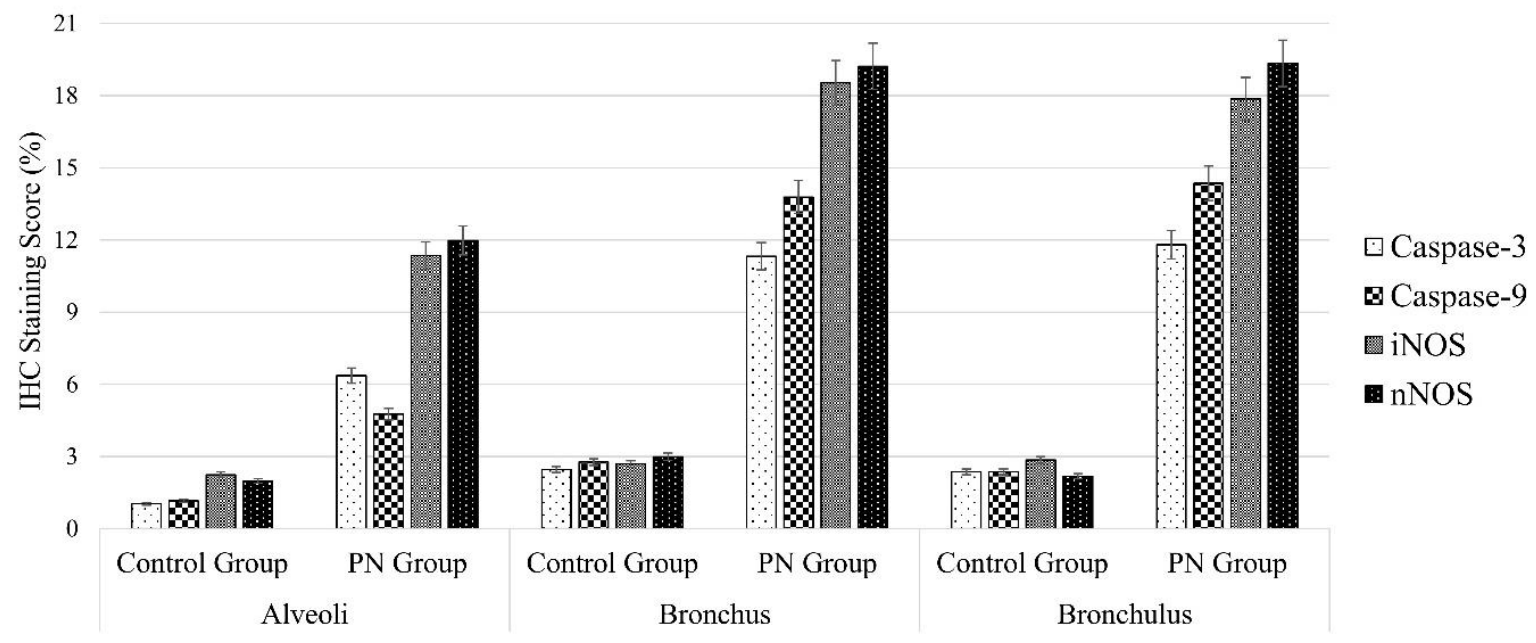

Figure 2. Immunohistochemical staining rate of the lungs. Control group and Pneumonia group (PN Group)

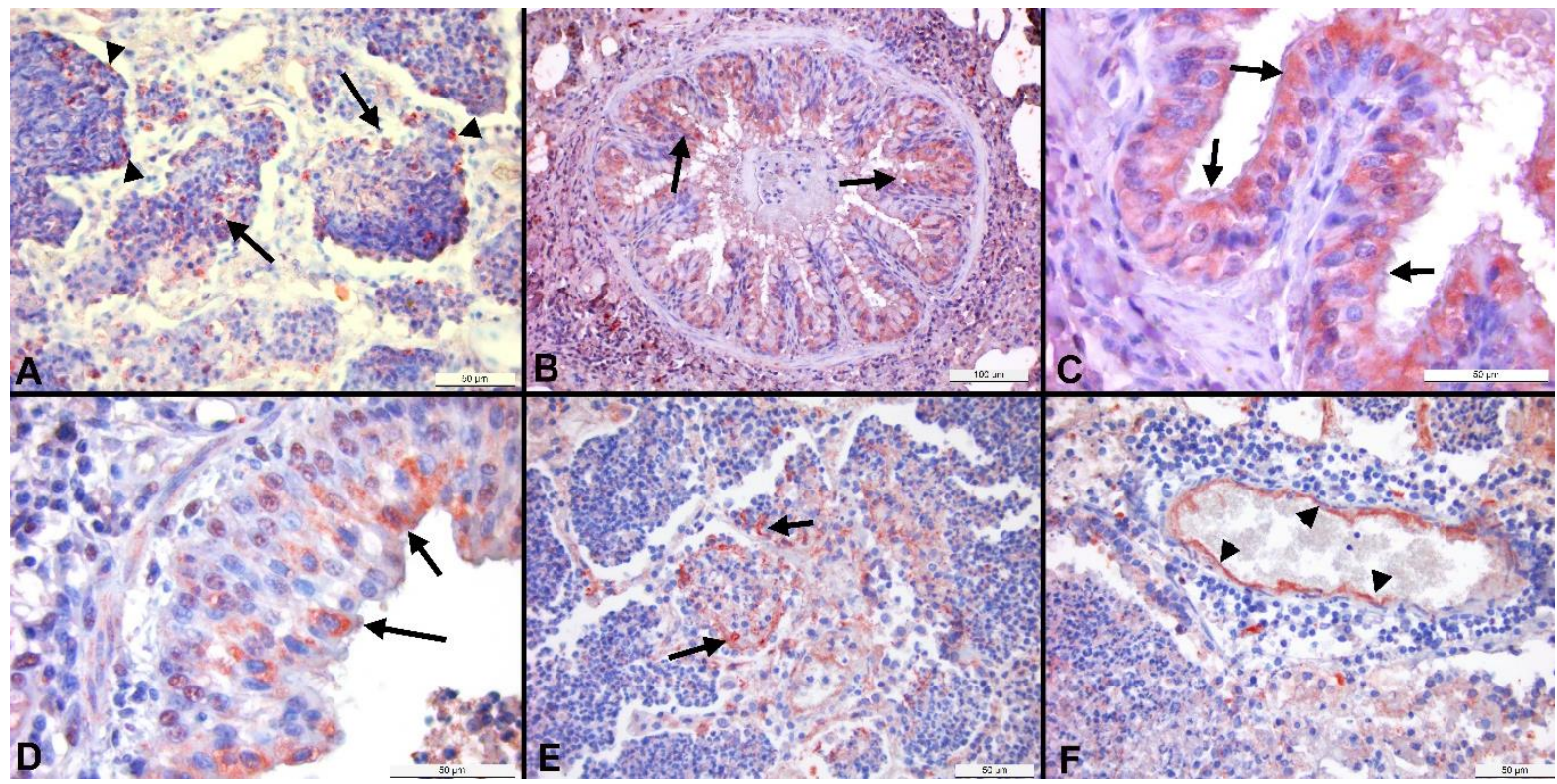

Figure 3. Immunohistochemical staining of the lungs.

A. Caspase- 3 immunopositive staining in the epithelia of the alveoli (arrowheads) and inflammatory cells in the lumens (arrows). AEC. Bar: $50 \mu \mathrm{m}$. B. Caspase-9 positive staining in the epithelia of the bronchiole (arrows). AEC. Bar: $100 \mu \mathrm{m}$. C. Close-up view of Caspase-9 positive reactions in the epithelia of the bronchus. (arrows). AEC. Bar: $50 \mu \mathrm{m}$. D. nNOS immunopositive epithelial cells in the bronchus (arrows). AEC. Bar: $50 \mu \mathrm{m}$. E. iNOS positive immunoreactions in the epithelia and inflammatory cells in the lumens of the alveoli (arrows). AEC. Bar: $50 \mu \mathrm{m}$. F. iNOS immunopositive staining in the endothelial cells of the blood vessel (arrowheads). AEC. Bar: $50 \mu \mathrm{m}$. 


\section{Discussion}

$\mathrm{PP}$ is the one of the important infectious calf disease in the world as well as in Turkey. The causative agents are Pasteurella multocida type $A$ and Mannheimia haemolytica type A. Although the disease progresses with less mortality compared to previous years, there are still many points in understanding the pathogenesis (Caswell and Williams, 2016). Both Pasteurella and Mannheimia species are found in the normal nasopharyngeal flora of calves, but in conditions such as stress, temperature changes, and transport, they are activated and cause PP (Boyce et al., 2004). As demonstrated in the studies, factors such as endotoxin, lipopolysaccharide, adhesin and leukotoxin, in which agents increase virulence factors, have necrotic effects and apoptosis not only on inflammation cells such as neutrophils and macrophages, but also on alveolar, bronchial and bronchiole epithelia (Sun et al., 1999; Lopez and Martinson, 2017). In this study, it was aimed to determine apoptosis and NOS expressions in PP cases in the lungs of calves, and to investigate their role in pathogenesis of the disease.

Considering the character of the inflammation, $\mathrm{PP}$ is an acute and fatal lung infection of the calves that classified under fibrinous bronchopneumonia. PP is more severe than other pneumonias because fibrin in exudate affects not only the alveoli, bronchi and bronchiole but also pleura compared to other types of pneumonia (Çiftçi et al., 2015). It has been reported that virulence factors such as lipopolysaccharide, adhesin and leukotoxin, which have toxic effects on neutrophil granulocytes and cause degeneration especially in the inflammation zone. These degenerative changes show itself as oat-cell in histopathological examinations (Caswell and Williams, 2016). In this study, as reported in previous studies, congestion, red consolidation and gray consolidation stages and thickening of interlobular septum were detected due to fibrin, edema and inflammatory cell infiltrations.

In many previous studies, the causes of pathological changes of PP in the lungs have been tried to reveal. Praveena et al. (2010) found that Pasteurella multocida causes apoptosis in the lung. It has been reported that the necrotic changes in the airway epithelia in the lungs may be due to Caspase activity. Many bacterial toxins induce Caspase-dependent apoptosis, however, by which signaling mechanisms triggered this activation has not yet been revealed (Thumbikat et al., 2005). In another study, Caspase-3 positive staining was obtained in alveolar epithelial cells after lipopolysaccharide injections (Rudkowski et al., 2004). Periasamy et al. (2018) reported that lipopolysaccharides of Pasteurella multocida induce apoptotic effects on lymphocytes, macrophages and neutrophil granulocytes. In the present study, Caspase- 3 positive immunoreactions were found both in the alveolar, bronchial, bronchiolar epithelia, and in the lumens of these structures. Atapattu and Czuprynski (2005) stated that Mannheimia haemolytica leucotoxin causes an increase in Caspase-9 activity. In this study, Caspase-9 immunopositive staining was found in alveol, bronchial and bronchiole epithelia, as well as in inflammatory cells in lumens. It was determined that apoptosis was induced in airway epithelia of lung and inflammatory cells in PP cases of calves. Thus, it can be said that apoptosis is induced by Caspase- 3 and also uses the intrinsic pathway by Caspase-9.

In a previous study, NOS activity has been shown to increase after LPS administration in vitro Pasteurella multocida infection (Periasamy et al., 2018). However, the functional roles of NOS in PP cases have not been fully elucidated. In a study, the effects of lipopolysaccharides on iNOS and nNOS activities were investigated in sepsisinduced lung apoptosis, and iNOS was found to play a role in increasing lung injury, whereas it was found to reduce apoptosis (Rudkowski et al., 2004). In another previous study, researchers have obtained the iNOS positive reactions in the alveol, bronchus and bronchulus epithelia as well as in the inflammatory and necrotic cells in these structures of lumens in Mannheimia haemolytica induced bronchopneumonia (Fligger et al., 1999). Although nNOS is known to be expressed primarily in central and peripheral neurons, it has been reported to be expressed in histological structures such as airway epithelium, smooth muscle cells, vessels and submucosal glands in lung tissue (Zhou and Zhu, 2009). Although it is expressed in lung tissue in cases such as acute respiratory distress syndrome and acute lung injury in sheep, no studies have been conducted on the expression of calves in PP cases (Enkhbaatar et al., 2003; Westphal et al., 2008; Cox et al., 2009, Saunders et al., 2010). In this study, iNOS and nNOS positive reactions were detected in alveolar, bronchial and bronchiole epithelials in vascular endothels and peripheral neuron extensions in lung tissue in PP cases in calves.

In the conclusion, apoptotic markers such as Caspase-3 and Caspasae-9 and nitric oxide synthesis indicators such as iNOS and nNOS were expressed especially in the epithelia of alveoli, bronchi and bronchioles as well as in the inflammatory cells in the lumens of these structures. In PP cases, Caspase-3 expressions have been shown to trigger apoptosis, and this was demonstrated intrinsic pathway by the Caspase- 9 expressions in these cells. Apoptosis in the airway structures is thought to be caused by LPS that is an important virulence factor of bacteria. However, high expression of iNOS and nNOS revealed that it plays a role as a pro-apoptotic factor in the lungs. Thus, it was thought that apoptosis became more severe and revealed severe clinical findings by the high concentrations of iNOS and nNOS expressions. It can be said that the bronchial and bronchiolar epithelia play more roles in the pathogenesis of PP than the alveolar structures.

\section{References}

Atapattu DN, Czuprynski CJ. 2005. Mannheimia haemolytica leukotoxin induces apoptosis of bovine lymphoblastoid cells (BL-3) via a caspase-9-dependent mitochondrial pathway. Infect Immun., 73(9):5504-5513. DOI: 10.1128/IAI.73.9.55045513.2005.

Boyce JD, Lo RYC, Wilkie I, Adler B. 2004. Pasteurella and mannheimia. (Gyles CL, Prescott JF, Songer JG, Thoenin CO) Pathogenesis of Bacterial Infections in Animals. Third edition. Place of publication: Ames, Iowa. Blackwell Publishing. pp:273-294. 978-0-8138-2939-5.

Caswell JL, Williams KJ. 2016. Respiratory system. (Maxie MG) Jubb, Kennedy, Palmer's Pathology of Domestic Animals Volume 2. Sixth edition. Place of publication: St. Louis, Missouri. Elsevier Publishing. pp: 465-591. 978-0-7020-5318-4. 
Çiftçi MK, Ortatatlı M, Erer H, Hatipoğlu F, Özdemir Ö. 2015. Veteriner sistemik patoloji. First edition. Place of publication: Konya. Selçuk Üniversitesi Basımevi. 978-975-97351-5-9.

Cox RA, Jacob S, Oliveras G, Murakami K, Enkhbaatar P, Traber L, Schmalstieg FC, Herndon DN, Traber DL, Hawkins HK. 2009. Pulmonary expression of nitric oxide synthase isoforms in sheep with smoke inhalation and burn injury. Exp Lung Res., 35(2):104-118. DOI: 10.1080/01902140802446832.

Daff S. 2010. NO synthase: structures and mechanisms. Nitric Oxide., 23(1):1-11. DOI: 10.1016/j.niox.2010.03.001.

Enkhbaatar P, Murakami K, Shimoda K, Mizutani A, McGuire R, Schmalstieg F, Cox R, Hawkins H, Jodoin J, Lee S, Traber L, Herndon D, Traber D. 2003. Inhibition of neuronal nitric oxide synthase by 7-nitroindazole attenuates acute lung injury in an ovine model. Am J Physiol Regul Integr Comp Physiol., 285(2): 366-372. DOI: 10.1152/ajpregu.00148.2003.

Fligger JM, Waldvogel AS, Pfister H, Jungi TW. 1999. Expression of inducible nitric oxide synthase in spontaneous bovine bronchopneumonia. Vet Pathol., 36(5):397-405. DOI: 10.1354/vp.36-5-397.

Förstermann U, Sessa WC. 2012. Nitric oxide synthases: regulation and function. Eur Heart J., 33(7): 829-837. DOI: 10.1093/eurheartj/ehr304.

Gaston B, Drazen JM, Loscalzo J, Stamler JS. 1994. The biology of nitrogen oxides in the airways. Am J Respir Crit Care Med., 149: 538-551. DOI: 10.1164/ajrccm.149.2.7508323.

Lopez A, Martinson SA. 2017. Respiratory system, mediastinum, and pleurae. (Zachary JF) Pathologic Basis of Veterinary Disease. Sixth edition. Place of publication: St. Louis, Missouri. Elsevier Publishing. pp: 471-560. 978-0-32335775-3.

Mcllwain DR, Berger T, Mak TW. 2013. Caspase functions in cell death and disease. Cold Spring Harb Perspect Biol., 5(4):a008656. DOI: 10.1101/cshperspect.a008656.

Periasamy S, Praveena PE, Singh N. 2018. Effects of Pasteurella multocida lipopolysaccharides on bovine leukocytes. Microb Pathog., 119:225-232. DOI: 10.1016/j.micpath.2018.04.030.

Philchenkov A. 2004. Caspases: potential targets for regulating cell death. J Cell Mol Med., 8(4):432-444. DOI: 10.1111/j.1582-4934.2004.tb00468.x.

Praveena PE, Periasamy S, Kumar AA, Singh N. 2010. Cytokine profiles, apoptosis and pathology of experimental Pasteurella multocida serotype A1 infection in mice. Res Vet Sci., 89(3):332-339. DOI: 10.1016/j.rvsc.2010.04.012.
Reed JC. 2000. Mechanisms of apoptosis. Am J Pathol., 157(5):1415-1430. DOI: 10.1016/S0002-9440(10)64779-7.

Rice JA, Carrasco-Medina L, Hodgins DC, Shewen PE. 2007. Mannheimia haemolytica and bovine respiratory disease. Anim Health Res Rev., 8(2):117-128, DOI: 10.1017/S1466252307001375.

Rudkowski JC, Barreiro E, Harfouche R, Goldberg P, Kishta O, D'Orleans-Juste P, Labonte J, Lesur O, Hussain SN. 2004. Roles of inos and nnos in sepsis-induced pulmonary apoptosis. Am J Physiol Lung Cell Mol Physiol., 286(4):793800. DOI: 10.1152/ajplung.00266.2003.

Saunders FD, Westphal M, Enkhbaatar P, Wang J, Pazdrak K, Nakano Y, Hamahata A, Jonkam CC, Lange M, Connelly RL, Kulp GA, Cox RA, Hawkins HK, Schmalstieg FC, Horvath E, Szabo C, Traber LD, Whorton E, Herndon DN, Traber DL. 2010. Molecular biological effects of selective neuronal nitric oxide synthase inhibition in ovine lung injury. Am J Physiol Lung Cell Mol Physiol., 298(3):427-436. DOI: 10.1152/ajplung.00147.2009.

Singh K, Ritchey JW, Confer AW. 2011. Mannheimia haemolytica: bacterial-host interactions in bovine pneumonia. Vet Pathol., 48(2): 338-348. DOI: 10.1177/0300985810377182.

Sun Y, Clinkenbeard KD, Clarke C, Cudd L, Highlander SK, Dabo SM. 1999. Pasteurella haemolytica leukotoxin induced apoptosis of bovine lymphocytes involves dna fragmentation. Vet Microbiol., 65(2):153-166. DOI: 10.1016/s03781135(98)00286-7.

Thumbikat P, Dileepan T, Kannan MS, Maheswaran SK. 2005. Mechanisms underlying Mannheimia haemolytica leukotoxin-induced oncosis and apoptosis of bovine alveolar macrophages. Microb Pathog., 38(4):161-172. DOI: 10.1016/j.micpath.2005.01.002.

Westphal M, Enkhbaatar P, Schmalstieg FC, Kulp GA, Traber LD, Morita N, Cox RA, Hawkins HK, Westphal-Varghese BB, Rudloff HE, Maybauer DM, Maybauer MO, Burke AS, Murakami K, Saunders F, Horvath EM, Szabo C, Traber DL. 2008. Neuronal nitric oxide synthase inhibition attenuates cardiopulmonary dysfunctions after combined burn and smoke inhalation injury in sheep. Crit Care Med., 36(4):11961204. DOI: 10.1097/CCM.0b013e31816a1a0c.

Zhou L, Zhu DY. 2009. Neuronal nitric oxide synthase: structure, subcellular localization, regulation, and clinical implications. Nitric Oxide., 20(4):223-230. DOI: 10.1016/j.niox.2009.03.001. 